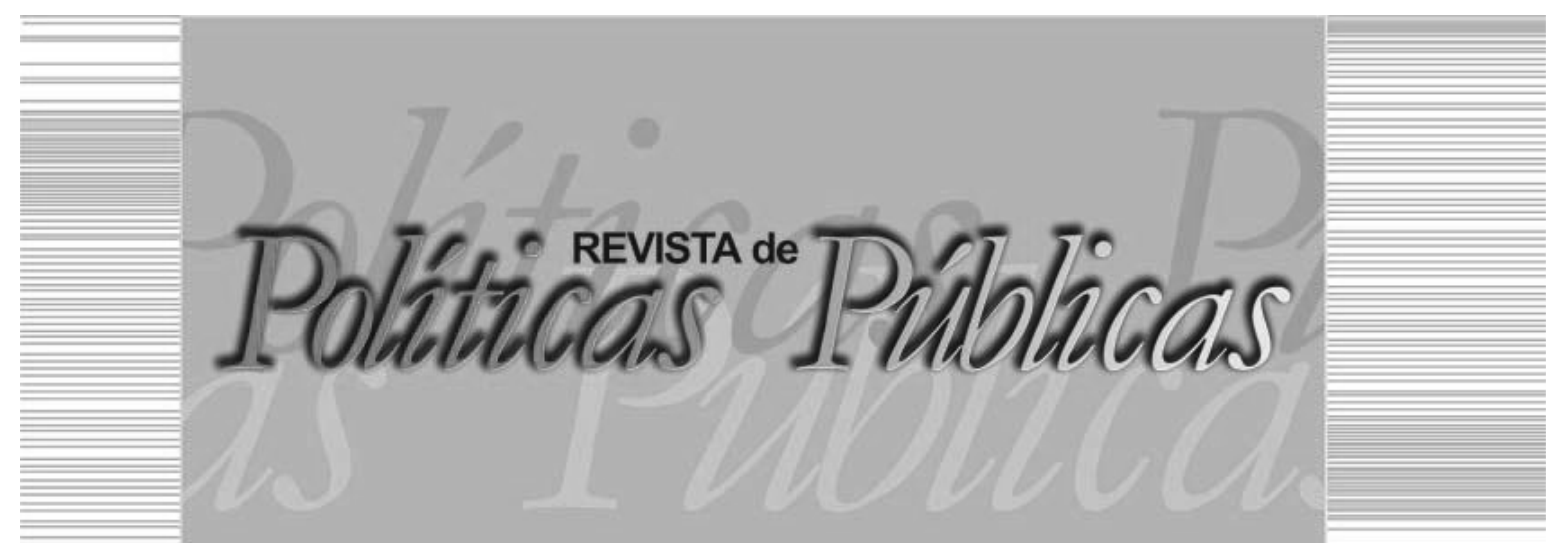

\title{
UMA ANÁLISE DA INSTITUCIONALIDADE DA CULTURA A PARTIR DO PROGRAMA CULTURA VIVA: perspectivas pela Companhia Quartum Crescente
}

Renan Gustavo Magalhães ${ }^{I}$

\section{Resumo}

O seguinte trabalho pretende apresentar o modo como uma política cultural é absorvida e reproduzida pelos grupos de cultura em nível local. Discute os avanços da institucionalidade da cultura no Brasil, pontuando os atuais desafios e as limitações desta análise, que parte do entendimento da institucionalidade enquanto leis e instrumentos técnico-normativos. Para isso, o estudo se centra no Programa Cultura Viva a partir da entrevista com Pontos de Cultura na Região do $\mathrm{ABC}$ paulista.

Palavras-chave: Pontos de Cultura, institucionalidade, políticas culturais.

\section{AN ANALYSIS OF THE INSTITUTIONALITY OF \\ CULTURE FROM THE LIVE CULTURE PROGRAM:}

perspectives by the Crescent Company Quartum

\section{Abstract}

This work intends to present how a cultural policy is absorbed and reproduced by cultural groups in local sphere. It discusses the progressions of the cultural institutionality in Brazil, pointing the current challenges and the limitations of

\footnotetext{
Bacharel em Ciências e Humanidades e em Políticas Públicas, Discente da Especialização em Gestão de Projetos Culturais pelo Centro de Estudos Latino Americanos sobre Cultura e Comunicação (CELACC) na Universidade de São Paulo (USP), Funcionário Público no Ministério Público Estadual de São Paulo (MPSP). E-mail: magalhaesrenang@gmail. com. Endereço: Ministério Público Estadual de São Paulo - MPSP: Rua Vinte e Três de Maio, 107 - São Bernardo do Campo - SP
} 
this analysis by the perspective that understands the constitution of institutionality as laws and technician and normative instruments. For these objectives, this study is focused on the Cultura Viva Program by the point of view of Pontos de Cultura in the $\mathrm{ABC}$ paulista region.

Key words: Points of culture, institutionality, cultural policies.

\section{INTRODUÇÃO: o programa Cultura Viva}

O Programa Cultura Viva é uma política completamente diferente de tudo o que já havia sido feito no campo das políticas culturais no país. Alterando a lógica que privilegia projetos e expressões culturais com um forte caráter mercadológico, fortalecida pelas políticas de financiamento por meio de renúncia fiscal que centraliza as decisões de apoio pelas empresas privadas, manifestações culturais de regiões interioranas e periféricas do Brasil passam a ser contempladas pelo olhar das políticas públicas do Estado. Os Pontos de Cultura, principal ação do Cultura Viva, incluem projetos ligados às culturas tradicionais, às matrizes africanas, à cultura indígena, ao hip-hop, além de grupos de teatro, dança e música comunitários que eram antes ignorados e passam agora a ser reconhecidos como manifestações culturais legítimas, dignas do respaldo do Estado para que sejam potencializadas e continuadas.

O Programa surge em um contexto de alteração dos rumos do Ministério da Cultura com a posse do então presidente Luís Inácio Lula da Silva e seu Ministro da Cultura Gilberto Gil. Lula e Gil herdam um cenário que Albino Rubim (2007) define como de tristes tradições - em uma visão que marca o campo das políticas culturais no país pela descontinuidade das ações, pelos vazios (contexto no qual diversas expressões culturais eram esquecidas e não obtinham apoio das políticas), e por fim, pelo autoritarismo, diante do qual as políticas culturais eram utilizadas para atingir objetivos ideológicos de governos autoritários. (RUBIM, 2007).

As políticas que se dão a partir desse período passam a ser estruturadas por conceitos norteadores mais amplos - que discutem o que é a cultura e qual é o papel do Estado nesse processo. Amplia-se o escopo dos projetos passíveis de apoio do Governo Federal, reconhecendo a diversidade cultural brasileira em um movimento que Gil (2003, p. 12) caracteriza, já em seu discurso de posse, como o Do-in antropológico, “[...] massageando pontos vitais, mas momen- 
taneamente desprezados ou adormecidos, do corpo cultural do país", de tal modo que se passe a "[...] avivar o velho e atiçar o novo".

Cultura, aqui, passa a ser entendida de uma maneira abrangente. Para fins metodológicos, o presente trabalho compreende (e se baliza nessa definição) que essa concepção mais abrangente da cultura está caminhando em direção a uma concepção antropológica. Para Danilo Júnior de Oliveira (2014, p. 17), cultura é um conceito em disputa e, por isso, de difícil definição: "[...] posto que diferentes campos do saber, com os mais diversos métodos, pressupostos e propósitos, buscam determinar ou ampliar, o sentido de cultura". Dessa forma, perspectivas distintas sobre o conceito de cultura servem para justificar as ações de grupos com interesses divergentes.

Diferente da concepção clássica da cultura ${ }^{1}$, a concepção antropológica amplia os significados do termo, em vez de restringir seu escopo. A partir do que John Thopmson (2011) define como função simbólica da cultura o conceito passa a ser relacionado às ações dos indivíduos no preenchimento de significados e na construção de sentidos a partir de símbolos. Esse processo descrito por Thompson encontra fundamentação teórica em Clifford Geertz (1983 apud THOMPSON, 2011, p. 176) que, a partir da concepção específica supracitada, resume cultura da seguinte maneira:

Cultura é o padrão de significados incorporados nas formas simbólicas, que inclui ações, manifestações verbais e objetos significativos de vários tipos, em virtude dos quais os indivíduos comunicam-se entre si e partilham suas experiências, concepções e crenças.

Isaura Botelho (2001, p. 74), então, conclui: “[...] dito de outra forma, a cultura é tudo que o ser humano elabora e produz, simbólica e materialmente falando".

A ampliação do conceito de cultura para Gil serve como estratégia de direcionamento das ações do MinC em uma iminente disputa de perspectivas teóricas que guiassem sua gestão. A escolha por trabalhar a cultura em seu sentido antropológico possibilita potencializar as distintas manifestações da diversidade cultural brasileira, em vez de dar suporte somente às manifestações de apelo mercadológico ou àquelas ligadas às belas-artes. Gilberto Gil (2003 apud OLIVEIRA, 2014, p. 8) em discurso apresenta, então, o que seria sua visão abrangente de cultura: 
[...] quando falamos de cultura, estamos empregando a palavra em sua acepção plena, em seu sentido antropológico. Cultura como a dimensão simbólica da existência social brasileira. Cultura como o conjunto dinâmico de todos os atos criativos de nosso povo. Como tudo aquilo que, no uso de qualquer coisa, se manifesta para além do mero valor de uso. Como aquilo que, em cada objeto que um brasileiro produz, transcende o aspecto meramente técnico.

Assim, nessa visão abrangente, Gilberto Gil busca caracterizar a cultura a partir de uma perspectiva norteadora que incluía três dimensões: a simbólica, a econômica e a cidadã. Com a dimensão simbólica, passa-se a considerar a cultura como plural, de onde participam diferentes culturas, marcadas pelas suas diversas expressões ligadas a costumes, línguas, crenças e práticas. A partir de então, a capacidade de construir símbolos é considerada algo inerentemente humano. Nesse movimento, "[...] ao reconhecer a existência da diversidade cultural, todas as diferentes culturas e seus produtos simbólicos ganham a mesma importância para o Estado." (MAGALHÃES, 2017, p. 6). Considerando a cultura a partir de sua dimensão econômica, passa-se a reconhecer nesse campo seu potencial de instrumento legítimo para o desenvolvimento. Já pela última dimensão, na concepção cidadã da cultura, há um movimento de retorno aos art. $215^{\circ}$ e $216^{\circ}$ da Constituição de 1988 , segundo os quais a cultura é vista como um direito. Caberia ao Estado ampliar o acesso da produção, fruição e difusão cultural para toda a população.

É nesse contexto, no qual políticas culturais ganham em importância e são elevadas de patamar, que é criado o Programa Cultura Viva. Lançado em 2004, o programa visa, a partir dos conceitos previamente apresentados que nortearam o MinC, na época, o lançamento de editais para o financiamento de projetos de entidades, grupos e coletivos culturais já atuantes em seus territórios. A partir, então, do recebimento de recursos financeiros, passa-se a potencializar e reconhecer como legítimas suas atividades.

O Programa também procura construir maneiras para que grupos passem a se articular entre si, através do fomento de encontros - as chamadas TEIAS, que estabelecem redes de atuação conjunta e auxílio mútuo. O Programa Cultura Viva é ainda composto por outros elementos, como o Agente Cultura Viva, Escola Viva, Ação Griô, Pontões e Pontinhos de Cultura, Prêmio Cultura Viva, ações de Cultura Digital e Pontos de Mídia Livre. Essas ações são articuladas em torno da imagem dos Pontos de Cultura. Como visto 
no texto de Célio Turino, idealizador do Programa, "[...] o Cultura Viva é concebido como uma rede orgânica de gestão, agitação e criação cultural e terá por base de articulação o Ponto de Cultura." (TURINO, 2009, p. 85).

Criada pela da Portaria Interministerial $\mathrm{n}^{\circ} 156$ em 2004, a política é inspirada nas ideias de Célio Turino e em sua experiência enquanto Secretário de Cultura de Campinas no final da década de 80 e início da década de 90 . A partir da demanda dos movimentos sociais de cultura da cidade excluídos das políticas culturais municipais, Turino lança as bases do que, mesmo em um curto período de tempo, serviria de inspiração para Gil no MinC.

O primeiro edital de Pontos de Cultura é lançado em 2004, e seleciona 210 projetos de grupos culturais de todo o país que seriam conveniados. Os grupos e associações interessadas em participar do edital deveriam elaborar um plano de trabalho para a realização de um determinado projeto cultural. Dessa forma, deveria conter no plano as metas, objetivos e a maneira como os projetos seriam executados - por exemplo, através da realização de oficinas, cursos, montagem de espetáculos, apresentações e circulação, etc. O plano deveria ainda conter o histórico de atividades, considerando suas experiências passadas e outros elementos que justificassem a seleção do grupo. Assim, partindo das ideias de protagonismo e autonomia, caberia ao grupo dizer o que e como seria feito, ou como visto em Turino (2009, p. 63. apud MEDEIROS; FARAH, 2014, p. 10), “[...] não dizendo o que as comunidades querem [fazer], mas perguntando como o querem". Uma vez contemplados, os Pontos deveriam ainda prestar contas periodicamente a respeito do emprego do recurso recebido, elaborando um relatório de atividades que contivesse fotos e vídeos anexados, além de outras formas de comprovação da realização dos projetos, como cartazes de eventos.

\section{O PAPEL DO ESTADO E A INSTITUCIONALIDADE DA CULTURA}

O Programa Cultura Viva é fruto de um período do Ministério da Cultura que buscou uma maior institucionalização da área, levando ao fortalecimento das instituições, a elaboração de planos e legislações que garantiriam uma melhor execução das políticas culturais no país. Por institucionalização, partimos da visão dos autores argentinos Rebón e Tasat (2015, p. 5), que definem o termo como 
o "[...] conjunto de normas formales e informales que regulan el comportamiento de los actores, las organizaciones, la calidad de las mismas, los modelos de organizaciòn y gestión los arreglos institucionales". Dessa forma, a maneira para avançar no cumprimento de metas e objetivos estabelecidos pela política seria resultado da mobilização desses fatores amplos supracitados.

Nessa perspectiva, a capacidade de um governo de planejar, executar e avaliar políticas passa pela sua capacidade institucional, assim como pela forma como 0 aparato estatal e suas estruturas organizativas, com suas normas, leis, procedimentos administrativos, recursos financeiros, humanos e técnicos estão ordenados para a realização de uma política.

Así, cuando se hace referencia a la capacidad de las instituciones, se trata también del modo en que la definición de roles y funciones, los procedimientos administrativos y los recursos humanos disponibles permite hacer frente a los problemas de gestión que se presenten. (REPETTO, 2003 apud REBÓN; TASAT, 2015, p. 7).

A cultura no Brasil passa ao longo do século XX por diversos avanços e retrocessos com a criação de instituições e a atuação sistemática do Estado Brasileiro nas políticas culturais - mesmo que enfrentando os desafios da descontinuidade, dos vazios e do autoritarismo - o que resultou em um acúmulo institucional, técnico e teórico significativo na área. A presença de um elemento legislativo que conferisse legitimidade ao campo se apresenta em seu grau máximo, teoricamente, com a Constituição de 1988, segundo a qual, de acordo com os art. $215^{\circ}$ e $216^{\circ}$, a cultura passa a ser vista como um direito da população e de atuação obrigatória do Estado.

O contexto de criação de ações voltado para a diversidade cultural no país passava então pelo desafio de consolidar mecanismos que garantissem a produção de políticas culturais a médio e longo prazo, superando políticas de governo que seriam transformadas em políticas de Estado. (RUBIM, 2017). Em ritmo lento, o Plano Nacional de Cultura em 2010 e o Sistema Nacional de Cultura, através de Emenda Constitucional em 2012, são aprovados visando este objetivo. O PNC permitiu o estabelecimento de objetivos para a área da cultura durante 10 anos, de modo que possibilitasse o acom- 
panhamento e a avaliação do cumprimento das metas e ações no período.

O SNC procura articular os entes federativos na proposição das políticas culturais de maneira integrada. A adesão por parte de estados e municípios deve ser precedida obrigatoriamente pelo estabelecimento de um órgão específico para a cultura, um conselho de cultura e um fundo para o recebimento de recursos. O mecanismo passa ainda pelos Planos Estaduais e Municipais de Cultura, aos moldes do PNC, adaptados às devidas escalas e realidades, resultando no chamado CPF da Cultura - Conselhos, Planos e Fundos. Em tese, o Sistema Nacional de Cultura garantiria o fortalecimento das políticas culturais em nível regional e local, proporcionando recursos para a cultura em locais com baixa capacidade técnica e institucional. A esse respeito Rubim (2017, p. 70) pontua sua importância:

\begin{abstract}
A implantação do SNC potencializa estruturas e fluxos do campo da cultura e aumenta de modo significativo a institucionalidade cultural. A adesão ao SNC requer a construção de sistemas estaduais e municipais de cultura. Além da conjunção colaborativa dos entes federativos, o SNC prevê ainda a integração ou a constituição, quando for o caso, de subsistemas, a exemplo do Sistema Nacional de Museus e similares. Os sistemas articulam atores; racionalizam recursos; viabilizam trabalhos colaborativos; facilitam intercâmbios; possibilitam iniciativas inovadoras; ampliam a envergadura das intervenções; exigem gestão e profissionais mais qualificados; demandam normas e rotinas; viabilizam conexões federativas; garantem estruturas institucionais mais.
\end{abstract}

A observação dos instrumentos institucionalizados da cultura em São Caetano do Sul e Mauá, cidades analisadas em trabalho anterior (MAGALHÃES, 2017), serve de exemplo para mostrar as dificuldades da consolidação do SNC. Se a primeira apresenta um Plano de Municipal de Cultura bem estruturado, um Conselho ativo com eleições periódicas, a segunda possui um conselho municipal de cultura pouco atuante e teve apenas discussões, já interrompidas, a respeito da proposição de um Plano. Especificamente partindo da análise de seus fundos de cultura, o que se vê, apesar da existência nos dois exemplos, são fundos sem objetivos claros e com nítidas limitações na capacidade de captar recursos para financiar os projetos a que se propõem. Trata-se de instrumentos sem força para alterar suficientemente o cenário das políticas culturais locais. A impulsão do SNC passa pelo fortalecimento do FNC através de repasses fundo a fundo. Entretanto, pouco se pode fazer quando o próprio Fundo 
Nacional é desprovido de recursos para capitalizar os fundos regionais e municipais pelo país.

Atualmente está parado no Senado Federal o projeto de Lei $n^{\circ}$ 6.722 , de 29 de janeiro de 2010 que institui o Procultura, mecanismo que visa fazer do Fundo Nacional de Cultura o principal instrumento de financiamento à cultura no país, substituindo o financiamento através de renúncia fiscal que privilegia projetos culturais de caráter mercadológico (que ainda sim continuaria), como o protagonista das políticas culturais no Brasil. Na proposta é estipulado que $50 \%$ dos recursos do FNC sejam repassados para estados e municípios. Dessa forma, o fortalecimento do FNC é fundamental para que existam recursos financeiros significativos e para que os repasses fundo a fundo de fato venham a prover quantias significativas aos estados e municípios para a proposição e financiamento de projetos culturais no âmbito supranacional. Na visão de Rubim (2017, p. 66), a não aprovação do Procultura " [...] compromete a redefinição do papel do Estado e sua relação com as políticas de diversidade cultural implantadas desde 2003".

Quando discutimos o Programa Cultura Viva e a institucionalidade da cultura, um importante movimento de sua consolidação foi a Lei $n^{\circ} 13.018$, de 22 de julho de 2014², a chamada Lei Cultura Viva. Regulamenta-se o Programa absorvendo demandas dos Pontos de Cultura, alterando principalmente a prestação de contas e a adaptando à realidade dos grupos, que ainda realizavam esse processo a partir de normativas que regiam outras atividades do setor público, exigindo documentos e comprovações que não se encaixam na realidade do fazer cultural de associações pequenas da sociedade civil.

O movimento de fortalecimento do Programa Cultura Viva acarreta ainda na descentralização de suas ações, com o lançamento de editais por estados e municípios através de convênios em parceria com o MinC, através dos quais parte dos recursos são repassados do Governo Federal para os governos estaduais e municipais que, como contrapartida, além de se comprometerem com o restante dos recursos, realizam a gestão da política em nível local. Esse processo aproxima os Pontos de Cultura do poder público, conhecedores da realidade e das dinâmicas locais, favorecendo o diálogo.

A descentralização passava necessariamente pela articulação entre as esferas federativas para a proposição da política e substitui aos poucos os editais lançados de maneira direta pelo MinC, de 
modo a ampliar o número de pontos no território nacional. Essa etapa da política contribuiu para o fortalecimento do Sistema Nacional de Cultura, pois além de ampliar o número de Pontos de Cultura, foi possível promover o "[...] compartilhamento dos conceitos e objetivos do Programa junto aos governos locais." (HOPSTEIN, 2011, p. 56).

Por outro lado, a descentralização também " [...] inaugura um desafio para a gestão do programa, pois se defronta com problemas vindos da etapa anterior agora geridos em escala local." (MAGALHÃES, 2017, p. 10), evidenciando de tal modo as dificuldades históricas dos poderes locais em gerir os recursos e prestar auxílio aos pontos, devido à baixa capacidade administrativa. Essa visão vai de encontro a uma série de avaliações que passam a ser feitas de acordo com o Programa Cultura Viva em diversos momentos e etapas do programa. (INSTITUTO DE PESQUISA ECONÔMICA APLICADA, 2010; 2011; 2014; MEDEIROS; FARAH, 2014).

O período de avaliações da política demonstra que as normas e leis que regiam o programa de prestação não estavam adaptadas à realidade local dos pontos, trazendo complicações decorrentes para a gestão pública e para os grupos e organização. A falta de orientação do setor público e as exigências para a prestação de contas mostravam que o desenho da política ainda estava distante da realidade local. Esse fato é agravado pela inexperiência das associações em lidar com recursos públicos, principalmente aqueles pontos contemplados nos primeiros editais. A ideia que estava consolidada na facilitação da gestão em realidade se mostrou extremamente complexa do início ao fim, em um processo no qual os atrasos nos repasses se mostraram constantes, dificultando, assim, a gestão dos pontos e a continuidade de suas ações. A sobreposição de competências gerou vazios pela dificuldade em saber se determinadas funções eram de responsabilidade do $\mathrm{MinC}$ ou das secretarias de estado e municipais conveniadas. A divisão de funções e parcerias que facilitaria o processo, na verdade, por conta da baixa capacidade administrativa e pequeno número de funcionários capacitados, criou vácuos administrativos. A baixa capacidade técnica ainda ocasiona a falta de monitoramento e dificuldades na sistematização de informações. (MAGALHÃES, 2017).

Nesse movimento, tanto o Estado quanto os grupos culturais passam a ter suas características, modelos de gestão e responsabili- 
dades alteradas. Medeiros, Alves e Farah (2015) avaliam esse impacto a partir da perspectiva da reestruturação do aspecto organizacional, tanto dos pontos, quanto da política em si. Nesse sentido, a presença dos editais e convênios acarreta a necessidade dos grupos culturais em alterarem a forma que se organizam administrativamente para que possam adequar-se à lógica jurídica desses instrumentos. Como visto em Magalhães (2017, p. 15), "[...] trata-se de uma via de mão dupla, em que não só a pressão institucional interfere a estrutura desses grupos, mas a presença desses novos atores no campo da política cultural exerce influência no campo organizacional da cultura". A Lei Cultura Viva é um exemplo de como, através da pressão dos movimentos sociais de cultura, uma política de governo ganha força de lei e passa a ser constituída como uma política de Estado, interiorizando características das práticas de gestão dos grupos de cultura da sociedade civil.

A análise do Programa Cultura Viva, dessa forma, torna-se uma tarefa complexa, partindo da influência de diversos atores na política e de como estes são influenciados por ela. A partir do trabalho de Barbosa da Silva e Labrea (2017) é proposta uma avaliação da política através das redes que constituem o Cultura Viva, partindo da perspectiva dos diferentes agentes que influenciam no campo institucional do Programa. O resultado, então, dos olhares a respeito do Programa Cultura Viva - embrionária no Estado, mas tendo seus princípios fortemente ligados aos Movimentos sociais de cultura difere sensivelmente quanto à perspectiva de seus diferentes atores envolvidos nela, proporcionando diferentes leituras quanto as suas limitações, seus desafios, possibilidades e estratégias de atuação. A análise proposta por Barbosa da Silva e Labrea (2017) nos auxilia a entender as diferentes expectativas que diferentes atores possuem em relação a uma mesma política cultural. Se para os movimentos sociais, o discurso que envolve o Cultura Viva, a partir de conceitos como autonomia, protagonismo e empoderamento, dá aos grupos uma sensação de encantamento coletivo, ignorando questões burocráticas e administrativas, para os agentes públicos outras preocupações ganhariam maior importância, como por exemplo: "[...] ajustes finos nos processos de produção de editais, programação orçamentária, organização dos fluxos de pagamento, prestação de contas, definição de critérios de elegibilidade, objetivos e linhas de base para a expansão do programa etc." (BARBOSA DA SILVA; LABREA, 2017, p. 25). 
Dessa forma, um importante objetivo da análise a partir da perspectiva das redes é descentralizar a figura do Estado enquanto ator único do processo de produção da política pública, uma vez que se trata do resultado da interação entre os diversos atores nela envolvidos. Nesse movimento, passa-se a ver a sociedade civil como produtora da política pública e responsável pelo seu sucesso. Ao estado, cabe dialogar e fomentar as redes de modo que elas sejam potencializadas. Esse processo acontece dentro do Cultura Viva a partir das Teias, encontros e Fóruns, nos quais o Estado é posto como um articulador dessas relações. Barbosa da Silva e Labrea (2017, p. 39) ainda pontuam como responsabilidade do Estado o diálogo com os diferentes atores envolvidos na política, "[...] estabelecendo objetivos e resultados e oferecendo recursos institucionais e cognitivos para o desenvolvimento de estratégias comuns, a exemplo dos circuitos, percursos, processamento de projetos coletivos etc.". Apesar de não possuírem fronteiras limitadas e de não carecerem de agências coordenadores (BARBOSA DA SILVA; LABREA, 2017), a presença do poder público a partir de seus recursos - financeiros, burocráticos, institucionais - pode impulsionar as redes dos pontos de cultura, fortalecendo redes tanto temáticas quanto territoriais.

\section{ESTUDO DE CASO: o Programa Cultura Viva no ABC}

Para observar como uma política cultural se consolida e se institucionaliza em um determinado contexto, apresentamos parte dos resultados de pesquisa ${ }^{3}$ realizada anteriormente, no qual se buscou apresentar uma visão geral da política de Pontos de Cultura no ABC. No trabalho intitulado A produção cultural como política pública: uma análise da Política de Pontos de Cultura no $\mathrm{ABC}^{4}$, foi realizada uma análise de todos os editais de Pontos de Cultura que contemplaram projetos dos municípios do $\mathrm{ABC}$ paulista e, por meio da análise de diversas fontes de dados ${ }^{5}$, foi possível elaborar uma base confiável de todos os Pontos de Cultura da região. O trabalho seguiu com a realização de entrevistas com os Pontos, nas quais se procurou apresentar a experiência desses grupos culturais com o Programa Cultura Viva, entendendo como a política alterou sua produção cultural, sua gestão e seu relacionamento com o poder público local. A pesquisa também tratou de analisar de maneira inicial a presença dos mecanismos do chamado CPF da cultura - Conselho, Plano e Fundo -, nesses dois municípios em questão. 
Trata-se de uma análise do relacionamento entre os atores envolvidos na construção das políticas culturais locais a partir de uma visão dos Pontos de Cultura. É um movimento difícil e que leva em consideração o estado da discussão e abertura dos municípios para o tema da cultura, considerando ainda a capacidade de proposição de políticas culturais e mecanismos institucionalizados, por forma de lei, que garantam que estas sejam amplas, plurais e democráticas. Ao mesmo tempo, esse relacionamento passa pela também difícil tarefa de conciliar a limitação estatal - de capacidade técnica, discursiva e orçamentária -, com os interesses dos movimentos sociais de cultura, e com demandas e expectativas amplas, difusas e contraditórias.

Os Pontos de Cultura presentes no território do Grande ABC possuem características extremamente diversificadas, partindo de diferentes linguagens artísticas e estéticas, tipos de projeto e metodologia para a execução de suas ações. São coletivos de teatro, circo, hip-hop, cultura tradicional, audiovisual, música, entre outros, formando uma complexa e multifacetada rede de 57 projetos espalhados pelos seis dos sete municípios da região. Ao todo, sete editais contemplaram iniciativas do $\mathrm{ABC}$, propostos na esfera Federal, com os editais diretos do Ministério da Cultura; em nível Estadual, com projetos dentro do edital de 301 pontos de cultura lançado em 2009 pela Secretaria de Estado da Cultura; e no âmbito municipal, pelas redes fomentadas pelas prefeituras de São Bernardo do Campo e Diadema. Em um primeiro momento, Diadema lança uma rede após ter sido contemplada no Edital do Ministério da Cultura - Pontos de Cultura Governos, em que um valor do Minc foi repassado para a Secretaria Municipal de Cultura de Diadema para que esta propusesse uma rede de Pontos de Cultura em que iniciativas da sociedade civil fossem executadas em equipamentos públicos da cidade. Nesse edital, os grupos e coletivos culturais de Diadema passavam a executar seus projetos dentro de Centros Culturais do município. (MAGALHÃES, 2017).

Neste trabalho, optou-se por apresentar a entrevista realizada com a Companhia Quartum Crescente, de Mauá, contemplada no Edital Federal $n^{\circ}$ 03/2005. A entrevista foi baseada em questionamentos escolhidos de acordo com o objetivo da pesquisa - entender o impacto da política de pontos de cultura em coletivos da região do $\mathrm{ABC}$ e perceber suas perspectivas quanto às políticas culturais locais. As questões propostas buscaram tematizar a origem do grupo, suas atividades antes, durante e depois de terem sidos contemplados 
pelo edital de Pontos de Cultura, as estratégias de gestão para a sustentabilidade do grupo, o relacionamento com o território no qual os grupos estão inseridos e o relacionamento com o poder público. Esses questionamentos, entretanto, serviram como norte para os fluxos de informação espontânea que foram obtidos durante os encontros. A partir de então, busca-se apresentar os principais aspectos das entrevistas que contribuem com os objetivos deste artigo - de investigar a institucionalidade da cultura a partir do Programa Cultura Viva e especificamente a ação de Pontos de Cultura. As entrevistas com a Cia. foram realizadas presencialmente durante o ano de $2017 \mathrm{com}$ Ronaldo Moraes, fundador da Quartum Crescente, e Allan Teixeira, atual presidente da companhia. Outras eventuais dúvidas foram sanadas por e-mail ao longo da produção deste artigo.

A Companhia Teatral Quartum Crescente foi fundada em 1985 por jovens artistas da periferia da região de Mauá. Atuando como uma companhia amadora e independente, a Quartum Crescente ao longo dos anos realizou a montagem de diversos espetáculos e a pesquisa de diversos gêneros teatrais, contribuindo para a gradual profissionalização do grupo. Com os recursos obtidos pelas exibições e pelos prêmios em festivais de teatro pelo Brasil, em 2001 os membros do grupo decidem comprar um espaço permanente para o desenvolvimento de suas atividades. O chamado Espaço de Artes Quartum Crescente está inserido na comunidade do Jardim Oratório, em Mauá, onde desde então são desenvolvidas as diversas atividades do grupo. Desde 1985, a Cia. produziu mais de 20 espetáculos, participou de mais de 80 mostras e festivais de teatro e dança pelo país. Além das montagens, o grupo apresenta um núcleo de Dança Flamenca e oferta diversas oficinas de teatro e dança para crianças e jovens da região. (BONIOL, 2012).

Atualmente, o grupo possui com a prefeitura de Mauá parcerias que estão relacionadas a atividades de cunho social. Através do Projeto Cortinas Abertas, por meio de convênios do Fundo Municipal da Criança e do Adolescente, o grupo realiza oficinas com crianças e adolescentes do Jardim Oratório em situação de vulnerabilidade social, prestando atendimento psicossocial e encontros com seus familiares. À primeira vista, essas atividades se mostram como mecanismo possível para a obtenção de recursos de outras fontes para que o grupo possa continuar existindo e desenvolvendo suas atividades. No nosso encontro, o grupo explicou as dificuldades que envolvem uma parceria desse tipo, na qual é preciso desenvolver um 
projeto de cunho muito mais social que cultural, visando uma fonte de renda que consiga contribuir para o desenvolvimento de outras atividades do grupo, em paralelo. Entretanto, devido às características da Cia. e principalmente do território no qual está inserido, para Ronaldo Moraes é praticamente impossível dissociar o caráter social do caráter cultural.

Outro desafio apontado pelos membros da Quartum Crescente, no que diz respeito aos processos burocráticos para o acesso aos recursos públicos, foi gerir e prestar contas de sua execução. De acordo com Ronaldo, todos os editais que acessaram, incluindo o edital de Pontos de Cultura, possuem um aspecto burocrático oneroso que interfere no tempo para o pleno fazer cultural, a fruição e a criação estética e criativa dos grupos de cultura. Trata-se de um risco que pode acarretar problemas à dedicação prioritária aos aspectos administrativos e burocráticos da gestão cultural, colocando em segundo plano as atividades artísticas em si. Quando consideramos a limitação dos recursos financeiros e humanos, essa questão se torna ainda mais evidente.

Observa-se uma clara potencialização das atividades da Quartum Crescente com o edital de Pontos de Cultura, estabelecendo dois momentos distintos: antes e depois da participação na política. Esse marco fica evidente tanto nas falas de seus membros que relatam um aumento da capacidade de gerir projetos culturais e uma maior compreensão das políticas culturais e da constituição de redes de atuação conjunta, quanto pela observação de recursos de outras fontes que a Cia. passa a receber. Assim, o grupo é contemplado por editais da Petrobrás, da AES Eletropaulo, de dois editais do Programa de Ação Cultural (ProAC) - da Secretaria de Estadual de Cultura de São Paulo, além de ter recebido diversas premiações.

De acordo com Alves e Costa (2016 apud BOTELHO, 2001, p. 140), considera-se a cultura como "[...] a expressão das relações que cada indivíduo estabelece com seu universo mais próximo, o nível mais lógico e efetivo de atuação da política cultural é 'privilegiadamente municipal", pela proximidade, pelo reconhecimento dos problemas e das demandas e pela identificação com a situação. Entretanto, no caso da Quartum Crescente, o grupo se viu obrigado a procurar apoio prioritariamente em outros níveis de governo, participando de programas e políticas, tanto a partir do nível federal, como é o próprio caso dos pontos de cultura, como em nível estadual, em 
programas como o ProAc. O apoio municipal, como foi mencionado, evidenciou-se em atividades de caráter social, principalmente pela dificuldade no reconhecimento cultural da companhia e pela dificuldade em entender o artista como um profissional e o trabalho produzido por ele como digno de ser valorizado e de receber recursos financeiros para o seu desenvolvimento. Nas falas dos membros do grupo, a discussão em torno das políticas culturais, inevitavelmente, mostra-se muito mais avançada em outros níveis de governo.

A experiência adquirida durante os anos nos quais estiveram ligados à Política de Pontos de Cultura aumentou de maneira constante a capacidade técnica do grupo, fazendo com que a Quartum Crescente pudesse se manter de maneira sustentável, captando recursos de diversas fontes e editais, não se tornando, assim, dependente das políticas municipais de Mauá, sujeitas à descontinuidade, limitadas pelo orçamento e muitas vezes incapazes de entender a dinâmica cultural da própria cidade e as especificidades dos coletivos de cultura.

Como resultado desse processo, o grupo torna-se referência local no que diz respeito à gestão cultural. Como afirmou Ronaldo Moraes ao comparar as práticas de gestão da companhia com as da Secretaria de Cultura de Mauá: Nós do lado de cá, nós sabemos. Fica evidente na fala que o grupo possui um entendimento do fazer cultural diferente da visão institucionalizada no município - mais ampla, democrática e, como nos princípios do Programa Cultura Viva, antropológica. Trata-se de práticas culturais efetivas no território em que estão inseridos, consolidando redes de atuação que alcançam lugares e dialogam com pessoas que o Estado não consegue atingir ou sequer consegue enxergar. De acordo com Ronaldo, em vez de tentar criar um diálogo, ouvir e aprender, estabelecendo processos de cooperação, a prefeitura pula etapas e tenta se utilizar dos conhecimentos dos grupos de cultura, das redes de contato criadas e de sua influência nos locais nos quais atuam sem oferecer algo palpável em troca.

Os integrantes do grupo, apesar de se mostrarem um pouco mais esperançosos com o atual prefeito Átila Jacomussi, do PSB, no que diz respeito à gestão da cidade como um todo, em relação à pasta da cultura o clima ainda é de desesperança. Apesar disso, eles acreditam que a troca de gestão é positiva para a cidade, identificando um desejo de compreensão que nas gestões anteriores pouco havia. 
Vale ressaltar que as gestões anteriores eram do Partido dos Trabalhadores, e que mesmo estando alinhado com o executivo, havia no município uma dificuldade de entender não só o Programa Cultura Viva, como também outras políticas.

Entretanto, Ronaldo e Allan se mostraram cansados com a ideia de brigar e exigir uma melhor qualidade das políticas culturais no município, resultado das diversas decepções em gestões anteriores. O grupo aponta que canais de diálogo e participação, como conferências e fóruns, além do Conselho Municipal de Cultura já estiveram mais consolidados, o que, entretanto, não corroborou significativamente para uma alteração do cenário das políticas culturais da cidade. Ronaldo relata ainda conversas com grupos culturais de Mauá junto à prefeitura para a discussão do Plano Municipal de Cultura ${ }^{6}$. Porém, o plano elaborado em conjunto com a sociedade civil nunca foi assinado ou posto em prática.

\section{CONCLUSÃO}

O estudo de caso permitiu observar diferentes formas de relacionamento entre os grupos culturais e os territórios nos quais estão inseridos, tanto no que diz respeito ao local geograficamente limitado pelo bairro/comunidade, quanto em relação ao poder público e os diálogos estabelecidos com seus representantes. Foram demarcadas múltiplas visões a respeito do Programa Cultura Viva, das políticas culturais municipais, expectativas e desafios. As diferenças também são vistas no que concerne às redes e às relações construídas com outros grupos da sociedade, evidenciando os modos de consolidação dos grupos culturais, metodologias e mecanismos para a sustentabilidade de suas atividades e projetos.

A experiência da Cia. Quartum Crescente mostra um grupo muito mais ligado e, de certa forma, limitado pelo território em que atua, constituindo redes de atuação com membros da sociedade civil que não necessariamente possuem uma atuação cultural. As redes são, nesse sentido, fortemente territorializadas e a atuação da Companhia não se limita ao aspecto cultural. A relação com o poder público tem um caráter contestatório, o que evidencia uma nítida necessidade da sobrevivência do grupo. A Companhia, entretanto, continua em diálogo com a prefeitura, sobretudo por ser uma referência local, com mais de 30 anos de atuação na mesma comunidade de Mauá, na qual as redes constituídas por esse longo tempo de in- 
serção no território permitem a conexão com atores e grupos com os quais o poder público não consegue dialogar.

Diferente de outros coletivos analisados, diversos grupos consolidaram redes cuja força está relacionada mais aos temas do que aos territórios de origem, ligados pela atuação em setores como: hip-hop, cultura indígena, cultura tradicional, etc. O Ponto de Cultura Opção Brasil é um exemplo que, apesar de as limitações não permitirem aprofundamento, merece destaque: em relatos concedidos à pesquisa, seus membros afirmaram que a participação no Programa Cultura Viva permitiu uma maior experiência no diálogo com o poder público, na negociação com prefeituras para consolidar seus projetos e, em especial, com a prefeitura de São Caetano do Sul, onde o coletivo chegou a ter um de seus membros como Conselheiro de Cultura - em um espaço no qual os mecanismos institucionalizados das políticas culturais se mostram avançados em relação à média.

As observações do relacionamento dos grupos culturais com suas respectivas prefeituras mostraram que, apesar de existir diálogo e canais para o aprimoramento dessa conexão, os marcos teóricos e legais não garantiram a execução ou uma alteração significativa do cenário. A institucionalidade é somente efetivada a partir de canais de diálogo abertos ao entendimento das necessidades culturais do território. No caso estudado do ABC paulista, especificamente na prefeitura de Mauá, os grupos culturais evidenciaram a dificuldade de entendimento por parte do poder público no que se refere à política cultural e às suas ações. Ora, sem uma discussão mais avançada sobre o assunto, é impossível encontrar escopo para a garantia de políticas culturais concretas em nível local, o que leva os grupos a procurar metas em outros âmbitos federativos.

O poder público, por outro lado, não pode ceder a todas as demandas dos movimentos culturais, que são heterogêneas, complexas e muitas vezes contraditórias. Trata-se de uma suposição ilógica, ainda mais se considerarmos as limitações de orçamento. É necessário que o Estado pense em formas de fomentar as redes da sociedade civil, e que busque, ao mesmo tempo, fomentar seus mecanismos de participação para que consiga absorver as expectativas difusas e diversas dos grupos. O papel de propor formas de fortalecimento das redes da sociedade civil se dá por meio de mecanismos tais quais aqueles estabelecidos no Programa Cultura Viva, como as TEIAS, as 
Conferências e Fóruns, elementos propostos pela política, mas cujo protagonismo é dos grupos e coletivos culturais.

Em pesquisa anterior (MAGALHÃES, 2017) mostro que a iniciativa Pontos de Cultura - Governos, realizada em Diadema, pode em um momento posterior ser estudada com maior profundidade, pois o edital confere características ímpares à rede de pontos de cultura da cidade. $\mathrm{O}$ caso pode ser um caminho interessante para que se compreenda de que forma as redes de atuação e cooperação cultural podem ser fomentadas e incentivadas pelos municípios, contribuindo de maneira efetiva para a consolidação de um cenário cultural. Parte-se aqui de outra lógica, que não a maniqueísta, na qual os grupos culturais sempre são vistos em oposição às prefeituras, que em geral pouco compreendem a realidade dos coletivos culturais e suas percepções sobre as políticas culturais. Nesse caso, trata-se de uma lógica inovadora, que aproxima os grupos culturais da sociedade civil à gestão cultural municipal:

\begin{abstract}
A partir da perspectiva da democratização cultural, muitos equipamentos e centros culturais são construídos visando ampliar o número de pessoas atendidas pelas políticas sem, entretanto, que esses locais sejam de fato apropriados pela população, apresentando projetos e programas que muitas vezes não dialogam com os interesses de seus possíveis frequentadores. Ignora-se uma produção cultural já realizada nos bairros e o resultado disso são espaços públicos mal utilizados e pouco frequentados. A presença de projetos oriundos dos próprios bairros nesses locais, além de mais uma vez trazer reconhecimento para esses projetos, trazem consigo um público fidelizado e ativo, aumentando a perspectiva daqueles espaços serem bem-sucedidos. (MAGALHÃES, 2017, p. 32).
\end{abstract}

$\mathrm{Na}$ atual lógica do federalismo, o papel do município se torna muito mais complexo, passando de um mero prestador de serviço urbano para um importante agente no desenvolvimento econômico e social. Nesse sentido, a capacidade institucional se mostra de fundamental importância para a execução de políticas para a cultura, trazendo estabilidade e lógica para o planejamento da cultura em nível local. É válido ressaltar ainda, que, como reforçam Rebón e Tasat (2015), trata-se de um processo gradual, marcado por avanços e retrocessos, que está sujeito às restrições orçamentárias e às trocas de gestão no governo:

En este sentido, analizar las capacidades institucionales implica observar el sistema de capacidades de poder, recursos disponibles, 
legalidad y legitimidad y consolidación con que cuenta uma organización de la administración pública así como también su relación con las funciones y competencias que se asignan a los organismos responsables de ejecutar la política municipal de cultura. (REBÓN; TASAT, 2015, p. 6).

A institucionalidade da cultura em um município implica, para os autores mencionados (REBÓN; TASAT, 2015), os seguintes fatores: consolidação de ferramentas de gestão e de mecanismos de avaliação, um melhor planejamento para as políticas públicas e a iminente melhoria na qualificação dos profissionais atuantes na área. Ademais, na avaliação produzida por Rebón e Tasat, $(2015$, p. 11) uma carência identificada pelos municípios pela baixa institucionalização está na comunicação dos departamentos de cultura com instâncias superiores:

$$
\begin{aligned}
& \text { Las agencias de cultura de los municipios tienen un escaso diálogo } \\
& \text { con sus destinatarios, con instancias superiores (órganos de cultu- } \\
& \text { ra, provinciales y/o nacionales, de cuyas políticas son destinatarios } \\
& \text { a su vez), con otras agencias del próprio municipio, con la sociedad } \\
& \text { civil e incluso con otras agencias de cultura de otros gobiernos } \\
& \text { locales. }
\end{aligned}
$$

No âmbito de uma política complexa como a de Pontos de Cultura, pensada em nível federal e executada em nível local por grupos da sociedade civil, esse aspecto se coloca como fundamental. Em um primeiro momento, os governos municipais são colocados como intermediários do MinC e dos grupos e coletivos culturais beneficiados pela política, pela proximidade geográfica e político/institucional. Suas estruturas burocráticas atuam no sentido de fortalecer a cooperação e prestar auxílio aos grupos, ajudando-os a gerir um recurso cujo valor para grande parte dos pontos de cultura era novidade, assim como era novidade o enquadramento dentro das normas e especificidades de um edital público.

Em um segundo momento, a capacidade institucional do município está voltada para a proposição de convênios com o governo federal que possuem a finalidade de criar e fomentar redes municipais de pontos de cultura sustentáveis durante todo o ciclo. A institucionalidade pressupõe uma gestão sólida a ponto de evitar desgastes durante o ciclo da política, conseguindo seguir o planejamento e, por exemplo, realizar os repasses aos pontos de cultura sem atraso, um problema recorrente em diversos editais da política ao longo do tempo, incluindo o edital estadual de 2009. A comunicação com o 
órgão federal de cultura deve ser feita com constância e qualidade, alinhando os planejamentos. Além disso, mais uma vez se torna necessário a aproximação com os grupos beneficiados pelo recurso, auxiliando-os na gestão do montante e nas prestações de contas. Mesmo sendo uma política em nível federal, a institucionalidade dos governos locais é fundamental para o sucesso da gestão dos pontos de cultura - sobretudo nos casos dos editais municipais, mas também nos antigos editais federais.

Dessa forma, Rebon e Tasat (2015) propõem que, para avaliar as políticas culturais, é necessário que haja uma maior atenção no modo como se relacionam os atores que influenciam no desenho, na formação e na gestão dos planos e projetos culturais. É preciso, além disso, encontrar uma visão compartilhada pelas equipes do setor cultural dos governos que permita potencializar a realização dos objetivos. (REBÓN; TASAT, 2015). Assim, como visto em Barbosa da Silva e Labrea (2017), a questão da institucionalidade de uma política cultural não se limita apenas à questão de domínio técnico, por meio de orçamentos, leis e outros instrumentos normativos e aparatos legais, mas também, pela capacidade do poder público em absorver os discursos, diálogos e expectativas dos participantes da política. Para os autores, é fundamental para o processo de institucionalização de uma política "[...] a internalização de sistemas de valores, crenças e visões de mundo." (BARBOSA DA SILVA; LABREA, 2017, p. 13). Na discussão em torno do Cultura Viva, é válido o reconhecimento dessa perspectiva a partir do momento em que se considera uma política de atuação coletiva em redes de atores envolvendo sociedade civil e Estado, cada qual com suas idealizações e expectativas em torno do Programa. Sobre isso, Barbosa da Silva e Labrea (2017, p. 16) pontuam:

\begin{abstract}
Institucionalizar uma política pública significa estabelecer processos que conformem visões de mundo e formas de compartilhamento pelas comunidades de política, que justifiquem recursos e orientem seus usos. A operacionalização e a eficácia das políticas públicas dependem da capacidade de regulação coletiva das transformações organizacionais, de ajustes finos entre estruturas, sistemas de ação e visões de mundo.
\end{abstract}

A institucionalidade da cultura aqui almejada não pode ser apenas vista como um fim, pela aglomeração de mecanismos técnicos e legais que garantiriam a continuidade e o fortalecimento das políticas culturais. Na realidade local, como analisada nos estudos 
de caso, há uma nítida dificuldade, por parte dos governos, em absorver os diálogos e expectativas com os grupos culturais no processo de proposição de políticas culturais. Há ainda a dificuldade, mesmo nos casos em que já existem mecanismos institucionalizados consolidados, de propor políticas condizentes com o previsto nas leis, planos e conferências, de modo que os projetos políticos entrem em contradição com esses instrumentos. Nesse cenário, é necessário buscar a conciliação entre marcos legais, projetos políticos e expectativas dos movimentos culturais?

Essas pontuações levam a questionar se o que realmente falta é a institucionalização, considerando a presença de leis que fortaleçam as políticas culturais no país ou se, por outro lado, falta fortalecer esses mecanismos e regulamentá-los. No caso das políticas culturais, é ainda necessário pensar em formas de colocar em prática e efetivar as ideias que já norteiam os mecanismos institucionalizados das políticas culturais no país. No nível discursivo, a ideia antropológica da cultura capilarizou-se em diversas gestões, no âmbito das ideias políticas. É necessário, porém, mais do que assinar leis, regulamentá-las e validá-las, conferindo força e legitimidade ao campo das políticas culturais ${ }^{8}$.

Como visto em trabalho de campo, através da conversa com os grupos, a não efetivação de políticas elaboradas através de mecanismos de participação gera um sentimento de frustração e cansaço. Cria-se uma desconfiança quanto à real legitimidade desses mecanismos. Entretanto, é fundamental a ocupação desses espaços. A estruturação de novas bases teóricas, novas perspectivas em torno dos movimentos de cultura, a partir da sustentação em estruturas antigas, pré-concebidas, que impedem avanços significativos, ainda se mostra um desafio. Os vícios se repetem, assim como as limitações que impossibilitam uma ruptura completa no campo teórico. Dessa forma, é importante constituir novos olhares sobre as bases dos mecanismos de representação de dentro dessas estruturas, em um movimento de constante observação sob seu funcionamento.

Existe uma inerente limitação nos estudos propostos, em que se consideram os discursos dos atores do estudo de caso sem fazer juízo de valor. Uma possibilidade interessante para trabalhos futuros seria na contraposição a partir dos discursos dos membros do poder público, construindo um desenho mais completo a respeito do relacionamento entre o poder público e a sociedade civil. Outros 
exemplos práticos que dialogam com o teor deste trabalho podem ser avaliados com maior profundidade, como o caso de Diadema, que foi apresentado brevemente. Nesse exemplo, vemos que equipamentos públicos passam a ser sede de projetos de Pontos de Cultura, evidenciando uma interessante lógica de relacionamento entre Estado e grupos de cultura a partir dos pilares da autonomia proposto pelo Programa Cultura Viva. Ademais, o exemplo iniciado sobre São Paulo, nessa seção, pode ser outro caso interessante a ser analisado a partir dos pilares aqui discutidos, a partir de outra lógica, outra política, outro território.

\section{REFERÊNCIAS}

BARBOSA DA SILVA, F.; LABREA, V. As múltiplas redes do Programa Cultura Viva. Texto para discussão, Brasília, DF, p. 7-54, 2017.

BONIOL, R. L. Cia. Quartum Crescente e o Ponto de Cultura Entre Morros. 2012. 16 f. Pós-Graduação (Trabalho de Conclusão do Curso de Pós-Graduação em Gestão de Projetos Culturais e Organização de Eventos) - Universidade de São Paulo, São Paulo, 2012.

BOTELHO, I. Dimensões da cultura e políticas públicas. Revista São Paulo em Perspectiva, São Paulo, v. 15, n. 2, p. 73-83, 2001.

EAGLETON, T. A ideia de Cultura. Tradução: Sofia Rodrigues. 1. ed. Lisboa: Temas e Debates, 2003.

GIL, G. Discursos do Ministro da Cultura Gilberto Gil. Brasília, DF: Ministério da Cultura, 2003.

HOPSTEIN, G. O Programa Cultura Viva e os Pontos de Cultura: a constituição de uma rede democrática de produção político-cultura. In: FERRAZ, J. V.; LEMOS, R. Pontos de Cultura e Lan-houses: estruturas para inovação na base da pirâmide social. Rio de Janeiro: Escola de Direito do Rio de Janeiro da Fundação Getulio Vargas, 2011.

INSTITUTO DE PESQUISA ECONÔMICA APLICADA.

Cultura viva: as práticas de pontos e pontões. 2. ed. Brasília, DF, 2014.

Cultura viva: avaliação do programa arte, educação e cidadania. Brasília, DF, 2010.

Brasília, DF, 2011.

Pontos de cultura: olhares sobre o Programa Cultura Viva. 
UMA ANALISE DA INSTITUCIONALIDADE DA CULTURA A PARTIR DO PROGRAMA

CULTURA VIVA: perspectivas pela Companhia Quartum Crescente

MAGALHÃES, R. G. A produção cultural como política pública: uma análise da política de Pontos de Cultura no Grande ABC. Santo André, 2017. Relatório de iniciação científica. Edital UFABC PIC 01/2016.

MEDEIROS, A. K.; FARAH, M. F. S. Implementação e reformulação de políticas públicas: o caso do programa Cultura Viva. Revista do Serviço Público, Brasília, DF, n. 65, v. 1, p. 7-24, jan./mar. 2014.

MEDEIROS, A. K.; ALVES, M. A.; FARAH, M. F. S. Programa Cultura Viva e o campo organizacional da cultura: análise de políticas públicas pela perspectiva institucionalista. Revista de Administração Pública, Rio de Janeiro, v. 49, n. 5, p. 1215-1235, set./out. 2015.

OLIVEIRA, D. J. de. Direitos culturais e políticas públicas: os marcos normativos do Sistema Nacional de Cultura. 2014. Tese (Doutorado em Direito) - Faculdade de Direito da Universidade de São Paulo. São Paulo, São Paulo, 2014.

. O conceito ampliado de cultura e a concretização dos direitos culturais. In: CONGRESSO LATINOAMERICANO DE GESTIÓN CULTURAL, 1., Santiago. Anais... Trabalho apresentado no $1^{\circ}$. Santiago, 2014.

REBÓN, M.; TASAT, J. La cultura como política pública: la gestión de la cultura a nivel local. In: JORNADAS DE SOCIOLOGÍA, 10., Buenos Aires, 2015. Anais... Buenos Aires: Facultad de Ciencias Sociales, Universidad de Buenos Aires, 2015.

RUBIM, A A. C. Desafios da Institucionalidade Cultural no Brasil. Revista MATRIZes, São Paulo, v. 11, n. 2, maio/ago. 2017.

Políticas culturais no Brasil: tristes tradições, enormes desafios. In: Rubim, A \& Barbalho, A. (org.), Políticas Culturais no Brasil. Salvador: EDUFBA, 2007. p. 11-36.

THOMPSON, J. B. Ideologia e Cultura Moderna: teoria social crítica na era dos meios de comunicação de massa. Tradução: Grupo de Estudos sobre Ideologia, comunicação e representações sociais da pósgraduação do Instituto de Psicologia da PUCRS. 9. ed. Petrópolis, RJ: Vozes, 2011.

TURINO, C. Ponto de Cultura: O Brasil de Baixo para Cima. São Paulo: Editora Anita Garibaldi, 2009.

\section{Notas:}

1 Para entender os objetivos de se adotar uma concepção abrangente de cultura é necessário fazer a distinção desta com a concepção clássica. Na concepção clássica de cultura esta 
é vista como um conceito ligado à ideia de natureza, especificamente derivado dela (EAGLETON, 2003). Diante dessa perspectiva, compreendida a partir da estrutura etimológica do latim colere, o termo estaria ligado ao cultivo, dentro do campo da agricultura. Nessa analogia com o adubar e arar, cultura estaria relacionada a atribuição de significados, valores e concepções que alterariam o estágio inicial de um indivíduo. A cultura se aproxima, nesse processo de cultivo e alteração das práticas, costumes e hábitos de um indivíduo, de um caráter próximo da ideia de cidadania ou civilização. Nela, a cultura atuaria como um dispositivo de enquadramento da sociedade em torno de algum marco civilizatório. John Thompson (2011) define que esse conceito está ligado aos ideais iluministas de enobrecimento das faculdades humanas. Para Oliveira (2014, p. 19), a cultura nessa concepção torna-se um termo mais "[...] estreito e restritivo porque privilegia alguns trabalhos, obras e valores 'mais elevados', como os da academia e da arte, em detrimento dos outros saberes, fazeres e manifestações culturais"

2 "Escrito inicialmente por organizações culturais durante encontros periódicos dos envolvidos no programa Cultura Viva (as Teias), e apresentado pela deputada Jandira Feghali (PCdoB/RJ), em 27 de julho de 2012, foi aprovado na Comissão de Educação e Cultura o Projeto de Lei (PL) n 757 de 2011, que instituiu legalmente o Programa Nacional de Cultura, Educação e Cidadania - Cultura Viva, sendo que, em 28 de novembro

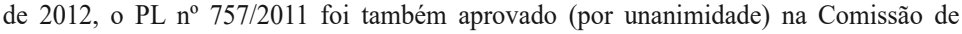
Finanças e Tributação da Câmara dos Deputados, e em 16/10/2013 foi apresentado ao Senado Nacional, identificado como PL n ${ }^{\circ}$ 90/ 2013." (MEDEIROS; ALVES; FARAH, 2015, p. 1226).

3 A pesquisa de iniciação científica em questão se insere num projeto mais amplo intitulado Autonomia municipal, poder local e a produção de políticas públicas: o caso do $\mathrm{ABC}$ Paulista, dentro do Edital Universal do CNPq por um grupo de cinco professores da UFABC. O projeto possui como objetivo analisar e avaliar a capacidade dos municípios do Grande $\mathrm{ABC}$ para produzir políticas públicas próprias em acordo com as necessidades e demandas locais e regionais, tendo em vista o processo de recentralização no federalismo brasileiro que, para alguns autores, representa uma ameaça à autonomia municipal assegurada pela Constituição de 1988. O projeto de Iniciação Científica em questão enfatiza especificamente as políticas públicas culturais propostas e implementadas por parte dos governos locais na região do Grande $\mathrm{ABC}$, delimitando-se na política de Pontos de Cultura.

4 Resumo do trabalho apresentado no VII Encontro de Iniciação Científica da Universidade Federal do ABC em 2017.

5 A base de dados que compõe a pesquisa foi obtida através de dados do portal Cultura Educa, da publicação Pontão 7 Cidades, prefeitura de Diadema, da publicação Catálogo da Rede de Pontos de Cultura do Estado de São Paulo de 2010-2012, da Secretaria da Cultura do Estado de São Paulo e de dados do Portal Cultura Viva.

6 Como visto no site da Prefeitura de Mauá (<http://www.maua.sp.gov.br/Not. aspx?NoticiaID=1979>).

7 Um exemplo prático de como a presença de mecanismos legais não resolve sozinha a questão da baixa institucionalidade, além dos mecanismos trabalhados nesse trabalho e conhecidos como CPF da cultura, pode ser observado também em São Paulo com o Programa de Fomento à Cultura da Periferia. Criado pela Lei ${ }^{\circ} 16.496,20$ de julho de 2016, o programa é uma vitória histórica dos coletivos culturais da periferia, apresentando diversos avanços institucionais que garantem o financiamento de grupos e projetos não contemplados pelas políticas culturais de caráter mercadológico, estabelecendo cotas de participação através da divisão dos distritos da cidade de São Paulo, priorizando projetos que não estão nos bairros centrais. Porém, mesmo regulamentado em forma de lei, a política assinada pelo então prefeito Haddad (PT), teve na sua segunda edição em 
UMA ANALISE DA INSTITUCIONALIDADE DA CULTURA A PARTIR DO PROGRAMA

CULTURA VIVA: perspectivas pela Companhia Quartum Crescente

2017, já com o prefeito João Dória (PSDB), uma queda de $22 \%$ de seu orçamento em relação ao ano anterior. Antes, o edital que seria lançado duas vezes ao ano, passou a ser apenas uma edição anual. O exemplo mostra que mesmo com o ganho de legitimidade política conferida pela lei, a institucionalidade ainda é limitada pela dificuldade do poder público em estabelecer o diálogo com coletivos, grupos e outros participantes do circuito cultural - com demandas histórias, difusas, complexas e por vezes contraditórias - e em entender de fato do que se trata determinado mecanismos de lei e como executá-los. Sem o amplo entendimento, as políticas culturais mesmo formalizadas em leis estão sujeitas a instabilidades, trocas de gestão, falta de orçamento e outros problemas recorrentes da área da cultura.

8 Um movimento recente interessante que caminha nessa direção está na investigação do Ministério Público sobre o não cumprimento da atual gestão às diretrizes do Plano Municipal de Cultura de São Paulo. Cria-se um sentimento de vigilância em relação ao cumprimento da lei, que sem ele os PMCs podem perder seu valor. 
